\title{
INCLUSÃO DIGITAL ATRAVÉS DE ENCONTROS LÚDICOS PARA O ESTÍMULO DO PENSAMENTO COMPUTACIONAL
}

\section{Digital Inclusion through of Playful Workshops to Encourage Computational Thinking}

Anelise Lemke Kologeski*

Vithória da Silveira Batista* ${ }^{* *}$

\begin{abstract}
Resumo: Esta iniciativa surge diante da necessidade de melhoria nos índices educacionais observados nos últimos anos, em especial aqueles informados pelo Instituto Brasileiro de Geografia e Estatística (IBGE) e pelo Índice de Desenvolvimento da Educação Básica (IDEB). Este trabalho apresenta uma experiência desenvolvida junto à comunidade escolar, com a oferta de oficinas lúdicas para o estímulo do pensamento computacional. A metodologia dos encontros consiste basicamente em dinâmicas alternativas ao ensino tradicional da sala de aula, promovendo momentos lúdicos para os participantes através do uso jogos e recursos digitais, a fim de promover a inclusão digital para alunos das séries finais do Ensino Fundamental de escolas públicas da região do Litoral do Rio Grande do Sul. As atividades são desenvolvidas com recursos da tecnologia da informação, em duas etapas: com o uso de jogos digitais, através de plataformas gratuitas, e com o uso da computação desplugada, oportunizando, assim, o atendimento das escolas independentemente dos recursos tecnológicos disponíveis, como um laboratório de informática, por exemplo. Nos encontros, jogos lúdicos são utilizados, estimulando o aprendizado dos participantes com base nos princípios básicos da programação, que são essenciais para a convivência em sociedade nos dias de hoje. No ano de 2019, já foram atendidos 200 participantes. Os resultados obtidos mostram que a experiência proporcionou melhorias de até $48 \%$ na compreensão de enunciados pelos participantes, além de despertar o interesse dos alunos pela tecnologia, promovendo uma educação integral e cidadã, oportunizando um aprendizado de forma criativa e significativa.
\end{abstract}

Palavras-chave: Encontros Lúdicos. Inclusão Digital. Pensamento Computacional.

\footnotetext{
Abstract: This initiative arises from the need to improve the educational rates observed in recent years, especially those reported by the Instituto Brasileiro de Geografia e Estatística (IBGE) and by the Índice de Desenvolvimento da Educação Básica (IDEB). This paper presents an experience developed with the school community, with the offer of playful workshops to

* Formada em Engenharia de Sistemas Digitais pela Universidade Estadual do Rio Grande do Sul, com Licenciatura e Formação Docente pela Universidade Federal de Santa Maria, e com Mestrado em Microeletrônica pela Universidade Federal do Rio Grande do Sul. Professora do Ensino Básico Técnico e Tecnológico do Instituto Federal de Educação, Ciência e Tecnologia do Rio Grande do Sul. ORCID: https://orcid.org/0000-0001-92578915. E-mail para contato: anelise.kologeski@osorio.ifrs.edu.br.

** Aluna do terceiro ano do Curso Técnico em Informática Integrado ao Ensino Médio do Instituto Federal de Educação, Ciência e Tecnologia do Rio Grande do Sul. ORCID: https://orcid.org/0000-0001-9292-1808. E-mail para contato: vithoria.sbatista@gmail.com.
} 
stimulate computational thinking. The methodology of the workshops consists basically of dynamic alternatives to the traditional classroom teaching, promoting playful moments for the participants through the use of games and digital resources, in order to promote the digital inclusion for students of the final grades of elementary school in public schools of the North Coast region of the Rio Grande do Sul State. The activities are developed with information technology resources, in two stages: with the use of digital games through free platforms, and with the use of unplugged computing, thus enabling the schools to attend regardless of the available technological resources, as a computer lab, for example. In the meetings, playful games are used, stimulating participants' learning based on the basic principles of programming, which are essential for living in society today. In 2019, 200 participants were attended. The results shown that the experience provided improvements of up to $48 \%$ in the participants 'comprehension of statements, as well as increasing the students' interest in technology, promoting integral and citizen education, providing opportunities for creative and meaningful learning.

Keywords: Playful Workshops. Digital Inclusion. Computational Thinking.

\section{Introdução}

A desigualdade no acesso à educação ainda é perceptível para a população brasileira, diante de dados coletados pelo Instituto Brasileiro de Geografia e Estatísticas (IBGE). Segundo a Pesquisa Nacional por Amostra de Domicílios Contínua (PNAD Contínua) do ano de 2018, a taxa de analfabetismo das pessoas de 15 anos ou mais de idade foi estimada em 6,8\% (11,3 milhões de analfabetos) em todo o território nacional (IBGE, 2018). Além disso: 48,1\% da população de 25 anos ou mais de idade estava concentrada nos níveis de instrução até o ensino fundamental completo ou equivalente; $27 \%$ tinham o ensino médio completo ou equivalente; e $16,5 \%$, o superior completo. Contudo, o acesso à educação de qualidade é direito fundamental para o desenvolvimento da cidadania e ampliação da democracia (IBGE, 2018).

Os investimentos públicos em educação são de extrema importância para a redução da pobreza, criminalidade e ampliação do crescimento econômico, bem-estar e acesso aos direitos fundamentais pela população (IBGE, 2018). E para que estes investimentos aconteçam, além do compromisso do Estado com a educação, que não tem suprido com excelência suas necessidades nos últimos anos, muitas iniciativas por parte da própria comunidade têm sido desenvolvidas e estimuladas para garantir uma educação de qualidade, democrática, com equidade e igualdade para todos.

Além dos preocupantes índices apontados pelo IBGE, a plataforma Agenda 2020 do Governo do Estado do Rio Grande do Sul (AGENDA 2020, 2019) também tem apresentado índices alarmantes para o Estado. Basicamente, a plataforma é constituída por um movimento social que visa transformar a realidade do Estado por intermédio da informação qualificada, da mobilização dos diversos agentes da sociedade e da ação conjunta voltada para o bem comum. Nela, são apresentados os resultados do Índice de Desenvolvimento da Educação Básica (IDEB) para o Rio Grande do Sul, desde o ano de 2007, como pode ser visualizado na Tabela 1, tanto para instituições estaduais quanto privadas, considerando-se as séries finais do ensino fundamental. Com os dados apresentados, é possível observar um pequeno progresso a cada edição, mas que ainda está longe de atingir a meta 
estipulada. Infelizmente, apesar dos esforços empreendidos pelo poder público e por amplos setores da sociedade no Estado, em especial pelos professores, ainda não foi possível atingir uma posição de destaque na educação básica diante do contexto nacional. Em parte, isso pode ser explicado pela descontinuidade das políticas educacionais, quando em educação os resultados se colhem no médio e longo prazo (AGENDA 2020, 2019).

Tabela 1 - Resultados do IDEB do Estado do Rio Grande do Sul desde o ano de 2007

\begin{tabular}{|c|c|c|c|c|}
\hline \multirow{2}{*}{$\begin{array}{c}\text { Séries Finais do } \\
\text { Ensino Fundamental }\end{array}$} & \multicolumn{2}{|c|}{ IDEB Atingido } & \multicolumn{2}{|c|}{ Meta Esperada } \\
\hline & $\begin{array}{c}\text { Rede } \\
\text { Estadual }\end{array}$ & $\begin{array}{c}\text { Rede } \\
\text { Privada }\end{array}$ & $\begin{array}{c}\text { Rede } \\
\text { Estadual }\end{array}$ & $\begin{array}{c}\text { Rede } \\
\text { Privada }\end{array}$ \\
\hline 2007 & 3,7 & 5,6 & 3,5 & 6,1 \\
\hline 2009 & 3,8 & 5,8 & 3,7 & 6,2 \\
\hline 2011 & 3,8 & 6,1 & 4,0 & 6,5 \\
\hline 2013 & 3,9 & 6,1 & 4,4 & 6,8 \\
\hline 2015 & 4,0 & 6,2 & 4,8 & 7,0 \\
\hline 2017 & 4,3 & 6,7 & 5 & 7,2 \\
\hline
\end{tabular}

Fonte: Agenda 2020 (2019).

Para justificar as causas dessa dificuldade em obter-se avanços nos índices educacionais apresentados, a Plataforma Agenda 2020 apresenta 4 justificativas elementares:

a) a reduzida capacidade de aplicação de recursos em Educação devido ao orçamento do Estado arcar com elevadas despesas previdenciárias: enquanto nos anos 70 aplicava-se $1 \%$ do Produto Interno Bruto (PIB) na previdência e $2 \%$ na educação, hoje 1,9\% do PIB é destinado à educação e 3,3\% à previdência;

b) o não pagamento do piso nacional do magistério, sendo que o Estado do Rio Grande do Sul tem a menor remuneração quando comparado a todos os outros Estados da federação, além de ser o único sem ter reajuste salarial nos últimos 4 anos, conforme dados apresentados por Santiago (2019);

c) a inadequação da educação escolar frente às exigências do século XXI, onde práticas educativas pouco inovadoras são utilizadas, evidenciando uma desconexão entre o currículo escolar e as demandas exigidas no mercado de trabalho;

d) e o conflito permanente entre sindicato dos professores e o governo do Estado, com ausência de pauta mínima de negociação.

Nesse contexto, cada contribuição vinda da comunidade tem sido de extrema importância para que se alcancem condições democráticas de acesso à educação, estimulando e incentivando os estudantes em sala de aula. Junto a esse tipo de iniciativas, o incentivo ao desenvolvimento e estímulo do pensamento computacional nas escolas têm se tornado algo de importante relevância social em nossa comunidade, uma vez que o contexto do pensamento computacional está inserido no cotidiano de cada indivíduo pertencente à sociedade contemporânea. De acordo com (BRACMANN, 2017), o pensamento computacional é uma distinta capacidade criativa, crítica e estratégica humana de saber utilizar os fundamentos da computação nas mais diversas áreas do conhecimento, possuindo a finalidade de identificar e resolver problemas de forma colaborativa através de passos claros, de tal maneira que uma pessoa ou uma máquina possam executá-los com eficiência. 
O uso do pensamento computacional, de forma conjunta com a tecnologia da informação, é uma tendência natural na sociedade, e praticamente todas as pessoas precisarão lidar com estes recursos em algum momento da vida, já que eles podem ser encontrados em praticamente todos os setores da sociedade, desde o produtor rural, que emprega tecnologia nos processos produtivos do campo, até nas grandes empresas, que fazem uso dos recursos mais modernos, sofisticados e automatizados em seus ambientes de trabalho.

Como forma de contribuir em prol de uma educação melhor e democrática, oportunizando também a inclusão digital, este trabalho foi desenvolvido com a proposta de oferecer encontros lúdicos para os estudantes das séries finais do ensino fundamental, na região do Litoral Norte do Rio Grande do Sul, realizando atividades relacionadas ao pensamento computacional e ao raciocínio lógico. Espera-se que o projeto seja capaz de promover a inclusão digital na comunidade, além de servir de incentivo para que os participantes possam se interessar pela área tecnológica. O desenvolvimento de um projeto que promove o estímulo de atividades envolvendo o pensamento computacional para alunos da educação básica de escolas públicas contribui para a inclusão, evolução e transformação digital no Brasil, expandindo a democratização do acesso à tecnologia.

\section{Fundamentação teórica}

O estímulo ao pensamento computacional, ao raciocínio lógico, ao uso de linguagens de programação e robótica, dentro das escolas, acontece de forma complementar ao ensino tradicional de sala de aula, já que normalmente as escolas não contemplam esses assuntos no currículo escolar. Contudo, muitas iniciativas já estão sendo realizadas, em alguns países ao redor do mundo, para favorecer o aluno na tomada de decisões e na resolução de problemas. $\mathrm{O}$ objetivo dessas ações é contribuir para o desenvolvimento do pensamento crítico, da criatividade e da capacidade de raciocínio, através do estímulo intermediado por meio de atividades lúdicas que envolvem o pensamento computacional, a lógica de programação e o raciocínio lógico.

Por exemplo, em 2013, o Reino Unido decidiu reformular o modelo antigo de aprendizagem, adotando um currículo que inclui obrigatoriamente o desenvolvimento de programação para os estudantes desde os 5 anos de idade (CHAMBERS, 2014). Quando os alunos chegam aos 14 anos, os professores passam orientações sobre como usar duas ou mais linguagens de programação, cabendo aos estudantes a escolha de continuar estudando a matéria e adquirindo as habilidades que serão relevantes quando se formarem. O compromisso do Reino Unido de ensinar noções básicas de programação desde cedo é considerado ousado, mas ainda não garante uma solução para a escassez de talentos na área da tecnologia, embora a iniciativa já seja bastante valorizada por preparar adequadamente os estudantes para um futuro cada vez mais tecnológico e digital.

Outro exemplo de país que tem incorporado a lógica de programação em sala de aula é a Austrália, que, desde 2015, tem substituído as disciplinas de História e Geografia por Programação de Softwares. De acordo com o Ministro de Educação Australiano que promoveu esta alteração, Christopher Pyne, as escolas devem ter ensino de alta qualidade em Ciência, Tecnologia, Engenharia e Matemática, e isso é de extrema importância para o futuro econômico da nação (BRAZILAUSTRALIA, 2015). 
Outros exemplos de investimento no ensino da programação são os Estados Unidos e a Alemanha, evidenciando que é preciso valorizar o ensino do pensamento computacional em sala de aula, incluindo recursos diversificados, incentivando o conhecimento de diferentes recursos tecnológicos desde o primeiro contato escolar, oportunizando um maior desenvolvimento ao país e a formação de profissionais qualificados para o mercado de trabalho. Contudo, mesmo diante de diversas iniciativas em âmbito mundial, o Ministério da Educação brasileiro não tem colocado em pauta a discussão sobre a inclusão de disciplinas que envolvam conteúdos relacionados ao pensamento computacional no currículo escolar, embora este assunto já esteja previsto na Base Nacional Comum Curricular (BNCC) associado ao uso da Matemática (BRASIL, 2019).

Sendo assim, o desenvolvimento de projetos que vão além da sala de aula tradicional (com aulas normalmente expositivas, conteudistas e repetitivas, sem experiências diversificadas), oriundos de iniciativas privadas ou de dentro da própria comunidade acadêmica, por diversas vezes na condição de projetos de extensão, são formas de incentivos para o estímulo do pensamento computacional além da sala de aula em seu modelo mais clássico.

O trabalho de Werlich et al. (2018) apresenta um mapeamento sistemático da literatura, visando verificar o estado da arte sobre o pensamento computacional no ensino fundamental, com uma pesquisa desenvolvida em 4 importantes plataformas de base de dados internacionais (IEEE Explorer, Google Scholar, Capes e ACM Digital Library). Dentre os resultados obtidos, os autores mostram que $65 \%$ das iniciativas que aplicam o pensamento computacional no ensino fundamental são provenientes de países como África do Sul, Áustria, Bélgica, China, Croácia, Eslovênia, Estados Unidos, França, Índia, Irlanda, Itália, Macedônia, Manila, Suécia e Tailândia, enquanto que o Brasil surge com 35\% do total das ocorrências dos artigos selecionados, mostrando a importância que este tema está recebendo no país. Entre as estratégias encontradas, observou-se a ampla utilização das ferramentas Alice, Lego, App Inventor, Scratch, Code.org, Raspberry Pi e jogos (com apoio de atividades da computação desplugada) para apoiar as aulas de pensamento computacional. De acordo com os autores, para a faixa etária entre 6 e 10 anos, o ensino de conceitos computacionais fica mais atrativo e divertido utilizando as técnicas da computação desplugada. Ainda, de acordo com os autores, o $4^{\circ}$ ano, $8^{\circ}$ ano e $9^{\circ}$ ano do Ensino fundamental são as séries que mais se destacaram nos artigos, enquanto que o método de avaliação de aprendizagem discente mais utilizado foi o acompanhamento do desempenho dos alunos nas aulas de Matemática.

Já o trabalho de Silva et al. (2018) também realiza um mapeamento sistemático da literatura, mas com o objetivo de identificar as estratégias para o ensino e a aprendizagem do pensamento computacional exclusivamente no Brasil. Os autores encontraram 61 artigos para o mapeamento proposto, considerando o período entre 2012 e 2017, nas plataformas de publicações brasileiras do SBIE, WIE, WCBIE, RBIE e RENOTE, dos quais 30 trabalhos compreendem a região Sul do Brasil, 16 são do Nordeste, 9 do Sudeste, 3 do Norte e 3 do Centro-Oeste. Além disso, os autores verificaram que o uso de ferramentas de programação visual e computação desplugada foram as estratégias mais comumente aplicadas, seguidas de jogos digitais.

Dessa forma, é possível observar que já existem diversas iniciativas que estimulam o uso das tecnologias da informação e comunicação no âmbito escolar, especialmente 
estimulando o desenvolvimento do pensamento computacional em sala de aula. Muitas delas, fazem uso da computação desplugada, sendo este um termo utilizado para definir a ausência do uso de computadores em atividades que envolvem jogos e quebra-cabeças (BELL et al., 2019). Entretanto, não podemos desqualificar a computação desplugada como uma proposta de inclusão digital, pois as atividades utilizadas por ela também lidam com conceitos primários de programação, mostrando que a integração dos conhecimentos relacionados à tecnologia da informação e comunicação com a sala de aula pode ser feita também de forma offline, sem o uso de recursos digitais.

Assim, para contribuir de forma positiva para o desenvolvimento da educação na comunidade onde a equipe de execução deste projeto está inserida, e diante da heterogeneidade da infraestrutura das escolas atendidas pelo nosso projeto, optamos por criar dois tipos de oficinas que estimulam o pensamento computacional e o raciocínio lógico, permitindo a participação de todas as instituições interessadas, independente da disponibilidade de recursos tecnológicos e digitais. Uma das oficinas consiste em utilizar a computação desplugada, sem o uso de computadores, e a outra compreende o uso de recursos digitais da tecnologia da informação e comunicação, necessitando de um laboratório de informática para a realização das atividades. Esta decisão foi tomada a fim de que todas as escolas pudessem ser atendidas com pelo menos uma das oficinas, ou com as duas, de acordo com o interesse e disponibilidade de cada escola participante. Além disso, as atividades trabalhadas estimulam a criatividade dos participantes, bem como auxiliam na melhor compreensão de enunciados e interpretação de textos, de tal forma que os participantes sejam capazes de melhor organizar e expressar suas ideias, com uma sequência lógica bem definida.

\subsection{Incentivo às mulheres}

Ao longo do projeto, a necessidade de um convite e uma divulgação especial para atrair a participação de meninas em áreas relacionadas com a tecnologia foi observada. Constatou-se uma grande desigualdade de gênero no curso Técnico de Informática oferecido pela nossa instituição, no qual a nossa equipe de execução está inserida: em 2019, há 141 meninos matriculados no curso, enquanto existem apenas 65 meninas, mostrando que elas representam aproximadamente um terço das matrículas no referido curso.

Infelizmente, este cenário não é exclusividade da nossa instituição. Essa desigualdade pode ser observada em diversas áreas que envolvem a tecnologia. Um exemplo disso é que, no Brasil, apenas $17 \%$ das pessoas que trabalham com programação são do sexo feminino (FRABASILE, 2018). Além disso, Achutti (2019) também apresenta dados da Pesquisa Nacional por Amostra de Domicílio do IBGE, a qual demonstra que só $20 \%$ dos profissionais que atuam no mercado de Tecnologia da Informação são mulheres. Ainda, de acordo com a autora, dados da ONU Mulheres Brasil revelam que as mulheres estão fora dos principais postos de trabalho gerados pela revolução digital, sendo que somente $18 \%$ delas têm graduação em Ciências da Computação e são, atualmente, apenas $25 \%$ da força de trabalho da indústria digital. Em uma sociedade cada vez mais tecnológica, formar meninas programadoras e inseri-las no mercado de trabalho é importante para combater a desigualdade de gênero. Além disso, quanto mais diversas forem as equipes nas empresas, mais completas serão as soluções criadas (ACHUTTI, 2019)

Um exemplo bastante motivador entre as mulheres, e recentemente divulgado na mídia, foi a notícia da primeira imagem de um buraco negro (FRANK, 2019). A equipe responsável 
por essa conquista teve a importante participação de uma mulher, chamada Katie Bouman, e seu rosto foi amplamente divulgado nas redes sociais. Ela participou da equipe que desenvolveu um algoritmo com a capacidade de decifrar milhares de dados astronômicos, resultando em uma ótima eficiência para enxergar fenômenos considerados até então como "invisíveis", como é o caso do buraco negro. Além disso, como forma de incentivo para as mulheres se interessarem pela tecnologia, alguns trabalhos e plataformas já estimulam a participação feminina em atividades voltadas para as mais diversas áreas tecnológicas, como por exemplo, a Plataforma Code.org (CODE, 2019) e o trabalho de Sass et al. (2018).

Nesse contexto, espera-se que o projeto aqui apresentado também tenha sua parcela de contribuição, a fim de instigar a curiosidade das meninas participantes pelas atividades desenvolvidas. Através de projetos e notícias que destacam a participação feminina, esperamos que a longo prazo as meninas possam ser encorajadas a tomarem seu respectivo lugar na produção de ciência e da tecnologia, protagonizando pesquisas, conquistas e descobertas, bem como estimulando outras mulheres a usarem a tecnologia sem medo, ou ainda a seguirem suas carreiras na área tecnológica.

\section{Metodologia}

Duas oficinas foram planejadas para introduzir conceitos básicos do pensamento computacional, incluindo atividades com programação que compreendem inicialmente a computação desplugada, no primeiro encontro, e o uso de recursos digitais, em um laboratório de informática, no segundo encontro. Cada encontro foi planejado para ter a duração de até 4 horas, atendendo como público-alvo os alunos das séries finais do ensino fundamental de escolas públicas da região do Litoral Norte do Rio Grande do Sul.

As atividades de computação desplugada são constituídas basicamente por jogos lúdicos, que podem ser realizados em sala de aula, sem a necessidade de um laboratório de informática, e que visam introduzir os conceitos básicos de programação com o uso de comandos para movimentação representados por setas. A ideia do uso de computação desplugada surgiu a partir da necessidade apresentada por algumas escolas interessadas na participação, mas que não possuíam computadores para o desenvolvimento das atividades.

Assim, o primeiro encontro introduz os conceitos de programação, com o uso da computação desplugada, enquanto que o segundo encontro consolida este conhecimento, através da programação em blocos com jogos digitais. $\mathrm{O}$ segundo encontro é realizado no laboratório de informática da própria escola (quando disponível) ou na instituição promotora das oficinas (IFRS Campus Osório).

Todas as atividades envolvem a capacidade de interpretação de texto do estudante, bem como o raciocínio lógico e o pensamento computacional, para que o aluno seja capaz de atingir os objetivos propostos no enunciado de cada atividade através de uma sequência bem definida de passos, como em um algoritmo. Cada participante recebe a assistência necessária dos bolsistas do projeto, durante o desenvolvimento das atividades propostas pela oficina, resolvendo as atividades de forma colaborativa.

\subsection{Primeiro Encontro: Computação Desplugada}


As atividades "Programação em papel Quadriculado" e "Estacionamento Algorítmico", das plataformas CODE (2019) e COMPUTACIONAL (2019) foram escolhidas para compor esta oficina.

A primeira delas, segundo a descrição informada pela própria plataforma, é uma organização internacional, sem fins lucrativos e com foco em oportunizar o acesso e o conhecimento à Ciência da Computação para indivíduos do mundo inteiro, bem como aumentar o índice de envolvimento das mulheres nesta área, através de atividades lúdicas envolvendo principalmente o uso de jogos digitais. Ela se propõe a oportunizar o aprendizado sobre computação para qualquer pessoa interessada, e tem o apoio de entidades reconhecidas mundialmente, como a Amazon, Google, Facebook e Microsoft. (CODE, 2019)

Já a plataforma Pensamento Computacional é nacional, e tem como objetivo apoiar redes de ensino e escolas que querem incluir temas como tecnologia e computação em seus currículos escolares (COMPUTACIONAL, 2019). Em ambas as plataformas, é possível encontrar atividades que vão desde a programação em blocos até a computação desplugada, permitindo assim atender os mais diversos públicos, em diferentes faixas etárias. Diante da demanda de algumas escolas participantes, as atividades foram adaptadas para que não houvesse a necessidade do uso de um laboratório de informática.

No encontro com a computação desplugada, os alunos recebem desafios, sendo que o primeiro deles consiste em reproduzir uma sequência de comandos em um papel quadriculado, a fim de descobrir qual será a imagem formada quando determinados quadrados forem pintados na figura, como o exemplo apresentado na Figura 1. O segundo desafio deste encontro consiste em movimentar um determinado veículo $(\mathrm{X})$ para fora de um tabuleiro, por meio de comandos que devem ser anotados e executados de forma ordenada. Para esta atividade, os veículos que estão na vertical só podem se movimentar na vertical, enquanto que os veículos que estão na horizontal só podem se movimentar na horizontal. Um exemplo de desafio proposto para essa atividade é apresentado na Figura 2.

Figura 1 - Exemplo da Programação com Papel Quadriculado
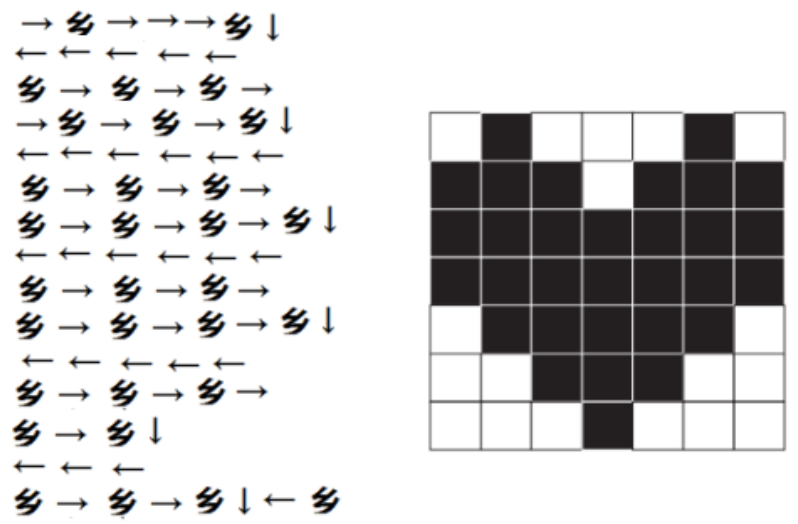

Fonte: Plataforma Code (2019). 
Figura 2 - Exemplo de desafio do Estacionamento Algorítmico

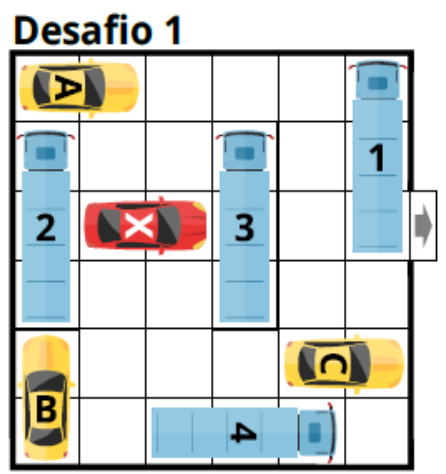

\section{Como jogar: usando apenas} os comandos $\rightarrow, \downarrow, \leftarrow$ e $\uparrow$, mova os carros, ou em linha vertical, ou em linha horizontal com o objetivo de tirar o carro $\mathrm{X}$ do estacionamento pela lateral direita (Saída).

Desafio 1
\begin{tabular}{|c|c|c|c|c|c|}
\hline VEÍ́CULO & \multicolumn{5}{|c|}{ MOVIMENTOS } \\
\hline$C$ & $\leftarrow$ & $\leftarrow$ & $\leftarrow$ & & \\
\hline 1 & $\downarrow$ & $\downarrow$ & $\downarrow$ & & \\
\hline$A$ & $\rightarrow$ & & & & \\
\hline 2 & $\uparrow$ & & & & \\
\hline$B$ & $\uparrow$ & & & & \\
\hline 4 & $\leftarrow$ & $\leftarrow$ & & & \\
\hline 3 & $\downarrow$ & $\downarrow$ & & & \\
\hline$X$ & $4 x$ & $\rightarrow$ & & & \\
\hline
\end{tabular}

Fonte: Plataforma Computacional (2019).

Assim, através das duas atividades apresentadas é que a oficina de computação desplugada é constituída, utilizando basicamente papel e caneta para as anotações, e um tabuleiro de papelão confeccionado para a movimentação dos veículos, também confeccionados em papelão, pela equipe de execução do projeto.

\subsection{Segundo Encontro: Recursos Digitais}

Para o planejamento das atividades desenvolvidas neste encontro, optou-se também pela utilização da plataforma digital gratuita Code (2019), por ser intuitiva, divertida e atrativa aos olhos dos participantes. Ela oferece diversos tipos de jogos, que abordam diversos temas, com personagens distintos, envolvendo noções espaciais, comandos condicionais e laços de repetição, por exemplo. As principais atividades escolhidas para serem utilizadas como tarefas deste encontro foram os jogos "A Fazendeira” e o "Labirinto Clássico”. Uma cena para cada um dos jogos mencionados é apresentada nas Figuras 3 e 4, respectivamente. Após a realização destas atividades, outros jogos são apresentados aos alunos, dando a eles a oportunidade de escolha de acordo com suas preferências pessoais: "Star Wars", "Minecraft" e "Frozen".

Tanto nas atividades de computação desplugada, quanto nas atividades que fazem uso dos recursos digitais, o principal objetivo é fazer com que o aluno compreenda a necessidade de formular uma sequência de passos bem definidos para conseguir atingir uma solução adequada para os problemas propostos durante as atividades. Essas sequências fazem com que, de forma colaborativa, os alunos percebam que mais de uma solução é possível para resolver o mesmo problema, assim como acontece com as mais diversas tarefas executadas por eles no dia a dia. 

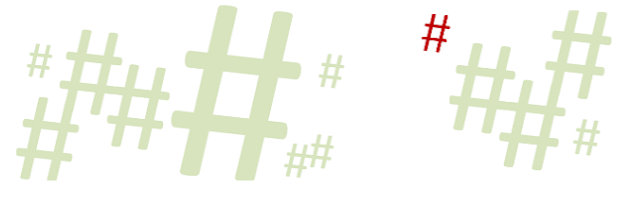

Figura 3 - Cenário do jogo "A Fazendeira"

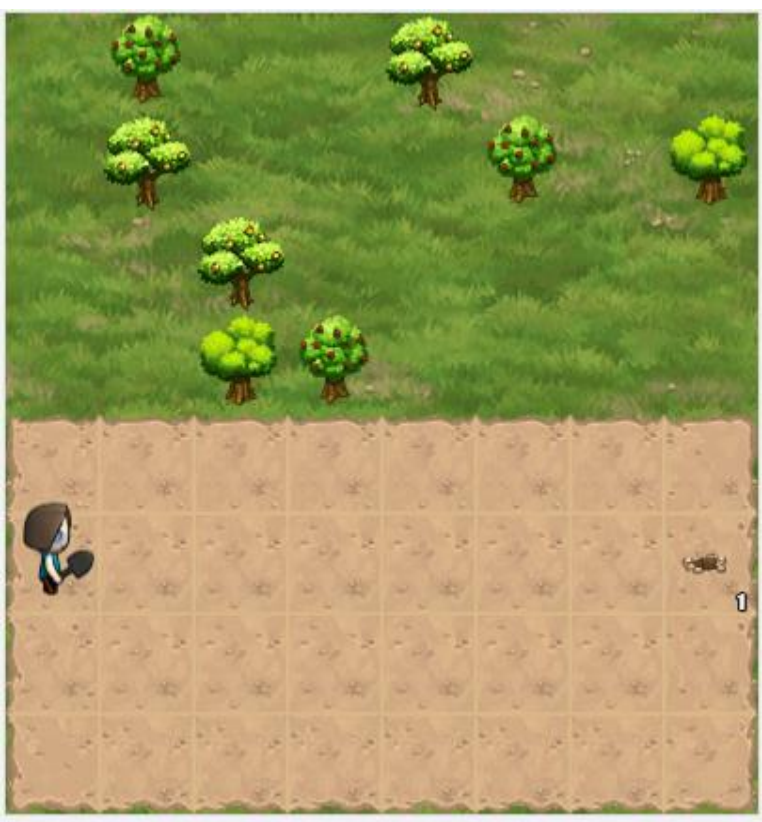

quando executar

enquanto houver caminho em frente $\nabla$

faça avance

preencha 1

Fonte: Plataforma Code (2019).

Figura 4 - Cenário do jogo "Labirinto Clássico"
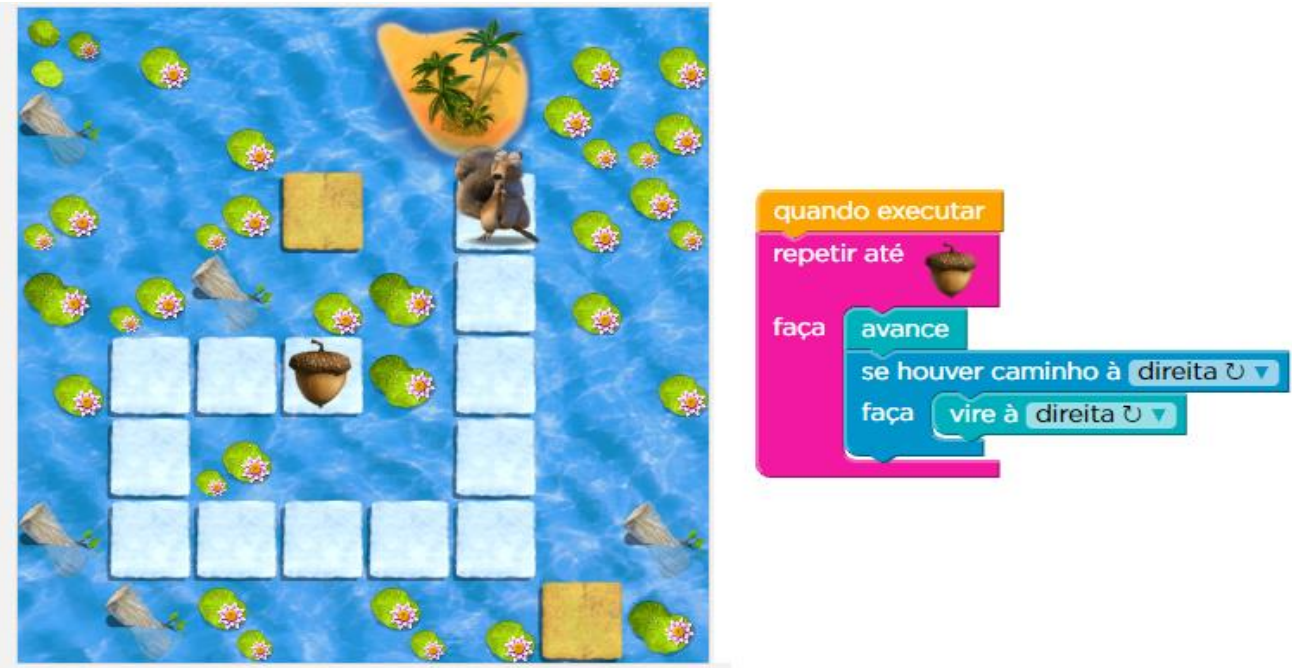

Fonte: Plataforma Code (2019).

3.3 Avaliação dos Encontros

Cada encontro é introduzido com a realização de um teste inicial, chamado de pré-teste, que serve para avaliar o conhecimento prévio dos alunos sobre enunciados que envolvem o pensamento computacional e o raciocínio lógico. Após o término de cada encontro, outro teste é realizado, chamado de pós-teste, que permite avaliar o desempenho do aluno após a realização das atividades. Ambos os testes são compostos por 5 questões que envolvem enunciados sobre os conteúdos trabalhados, focando no pensamento computacional e envolvendo as atividades trabalhadas. Essas questões são idênticas entre o pré e o pós-teste, para que os resultados 
possam ser comparados de forma justa. Usar o mesmo teste antes e depois permite que o aluno possa se autocorrigir, uma vez que durante a oficina ele explorou e aprendeu sobre o conteúdo ali abordado. Um exemplo de questão utilizada em cada encontro é apresentado nas Figura 5 e 6 , respectivamente.

Figura 5 - Exemplo de questão utilizada no teste do encontro desplugado

De acordo com a imagem ao lado, responda: quais são os 2 primeiros veículos que você precisa movimentar, respectivamente, para que 0 automóvel denominado $\mathrm{X}$ possa, posteriormente, ficar sem obstáculos à frente, para assim sair do estacionamento?

a) Carro E, Ônibus 2.

b) Carro G, Carro D.

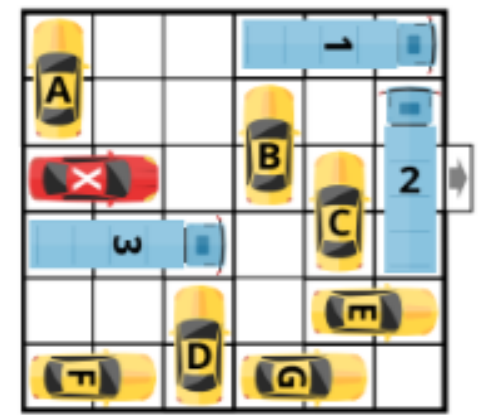

c) Ônibus 3, Carro F.

Fonte: Elaborada pelas autoras, 2019.

Figura 6 - Exemplo de questão utilizada no teste do encontro digital Levando em consideração a imagem à esquerda, qual bloco de comando que está faltando e deve ser introduzido na imagem à direita?
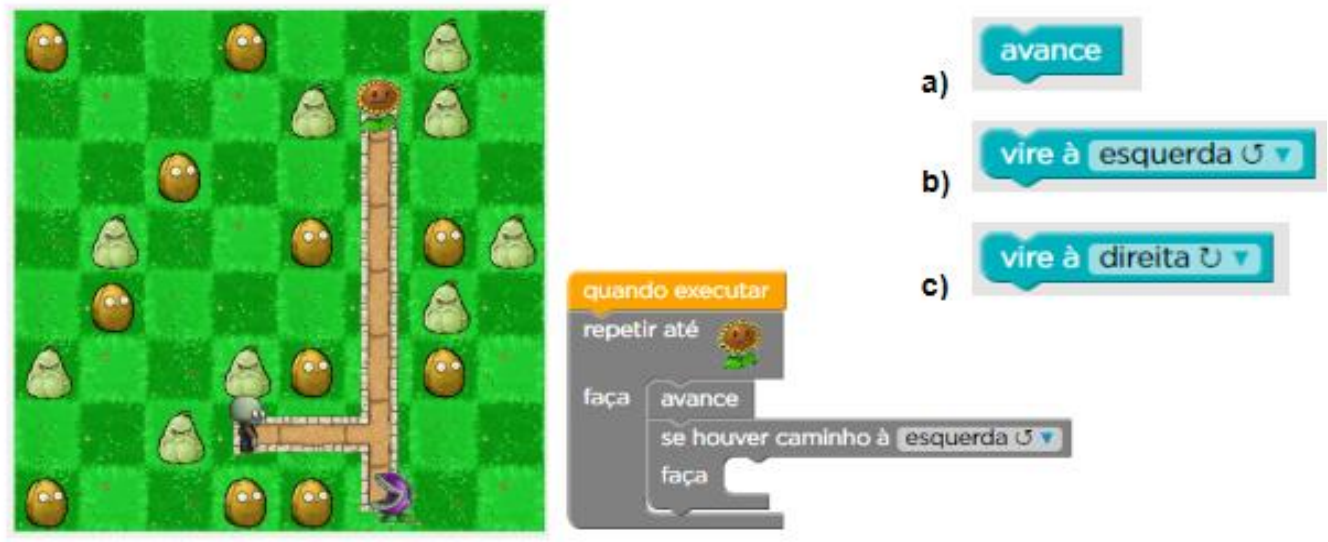

Fonte: Elaborada pelas autoras, 2019.

Com base nos resultados obtidos com a realização do teste inicial e do teste final em cada encontro é que os resultados deste trabalho puderam ser consolidados, conforme apresenta-se a seguir. 


\section{Resultados}

Durante a execução do projeto no ano de 2019, um total de 200 pessoas já foram atendidas, oriundas de 12 instituições distintas, das cidades de Tramandaí, Imbé, Capão da Canoa, Terra de Areia e Osório, todas do Litoral Norte do Estado do Rio Grande do Sul. Deste total de participantes, 169 participaram dos encontros com computação desplugada, e 141 participaram dos encontros com recursos digitais até o momento, sendo que alguns deles estiveram presentes em ambos os encontros, enquanto outros participaram de apenas um deles.

Para mensurar o aprendizado dos participantes, um teste foi realizado no começo de cada encontro, e outro foi realizado ao final, para fins de comparação. Na Figura 7, é apresentada a comparação entre a quantidade de acertos em cada questão do teste inicial e final do encontro desplugado. Na Figura 8, os resultados são apresentados da mesma maneira, porém levam em conta apenas o encontro digital. Uma síntese desses resultados pode ser observada na Figura 9, onde constatou-se que os participantes acertaram 72,57\% das questões iniciais para o encontro com computação desplugada, aumentando o número de acertos para 86,74\% ao final da oficina, representando uma melhoria de $14,17 \%$ na compreensão dos enunciados propostos. Para o encontro digital, inicialmente a quantidade de acertos foi de $44,80 \%$, chegando a $75,02 \%$ de acertos ao final da oficina, atingindo então uma melhoria de até 30,22\%.

Assim, com base nos resultados obtidos, é possível concluir que os encontros oferecidos contribuíram de fato para uma melhoria no aprendizado dos estudantes, oferecendo uma verdadeira oportunidade de inclusão digital a eles, já que muitas das escolas não tinham laboratório de informática para a realização das atividades, e por isso os alunos precisaram se deslocar até a instituição promotora das oficinas.

Figura 7 - Acertos por questão dos testes do encontro desplugado

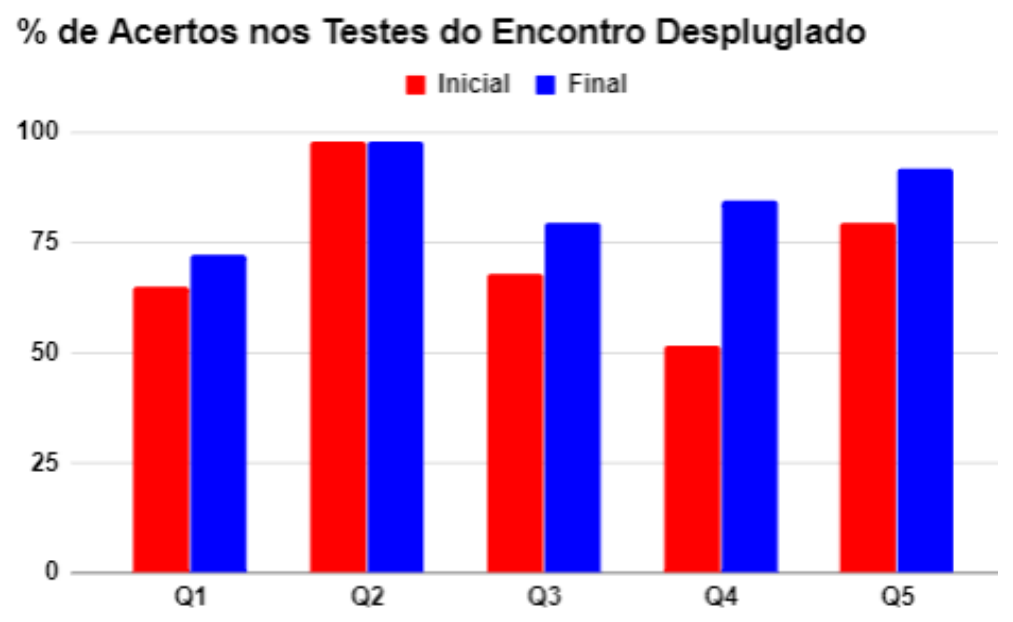

Fonte: Elaborada pelas autoras, 2019. 
Figura 8 - Acertos por questão dos testes do encontro digital

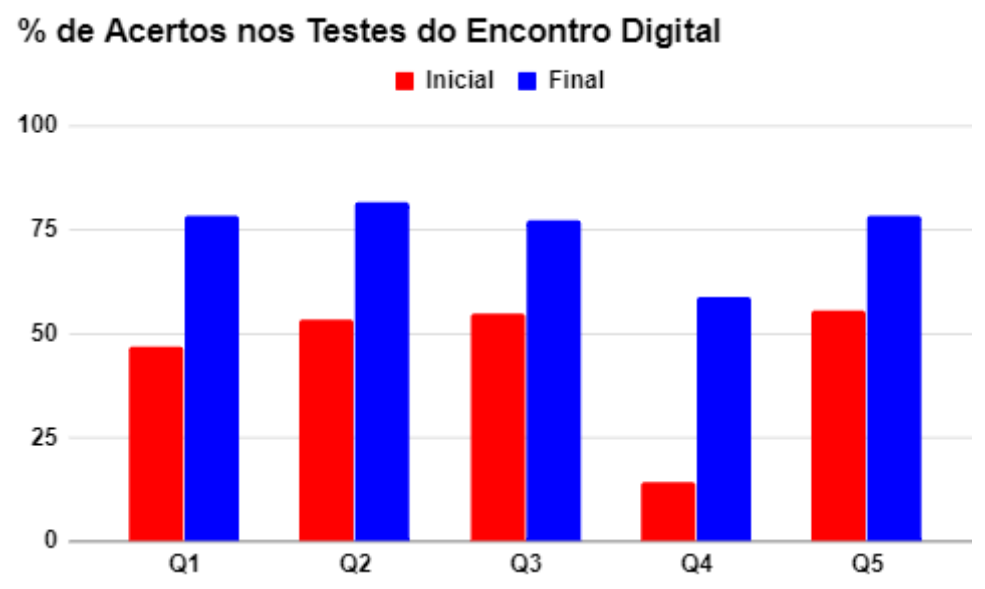

Fonte: Elaborada pelas autoras, 2019.

Figura 9 - Relação de acertos entre o teste inicial e final, para os dois encontros

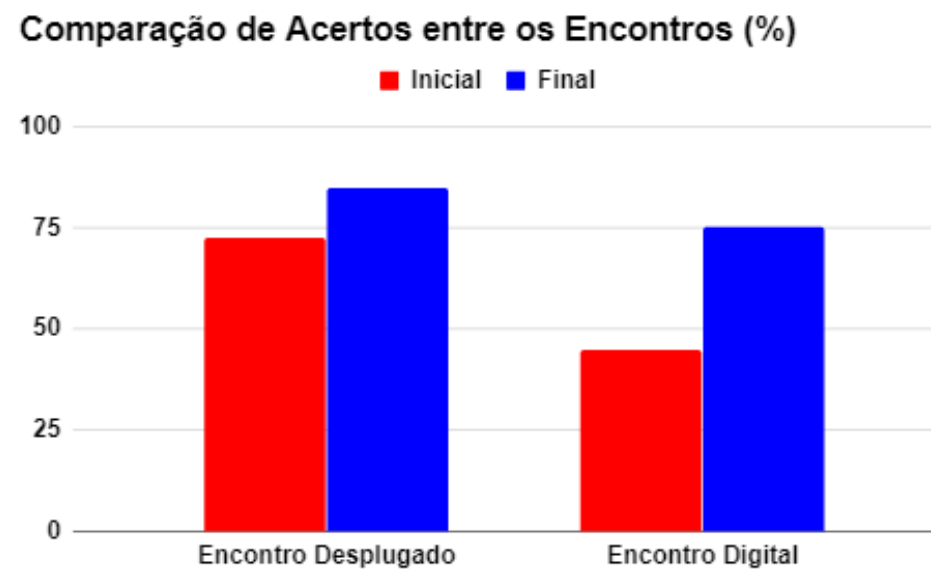

Fonte: Elaborada pelas autoras, 2019.

Além da contribuição para a aprendizagem dos participantes, quando eles puderam conhecer e explorar um pouco mais sobre o pensamento computacional e o raciocínio lógico, a equipe de execução do projeto também aproveitou a visita dos estudantes para oferecer a eles um momento onde pudessem conhecer as dependências e o funcionamento do IFRS Campus Osório, apresentando seus respectivos espaços e cursos, a fim de instigá-los na participação do processo seletivo do Curso Técnico em Informática Integrado ao Ensino Médio, que é público, gratuito e de qualidade. Na Figura 10, a média de idade dos participantes é apresentada, mostrando que todos participantes eram majoritariamente alunos formandos do ensino fundamental, com idades entre 13 e 16 anos, que ingressarão no ensino médio no ano seguinte, com exceção dos professores que também realizaram as atividades. 

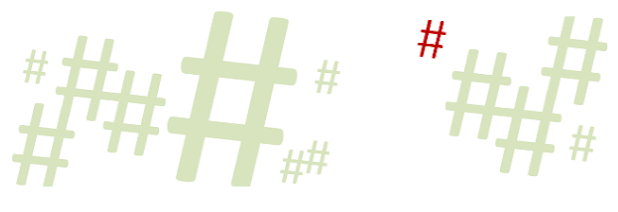

Figura 10 - Relação de idade dos participantes

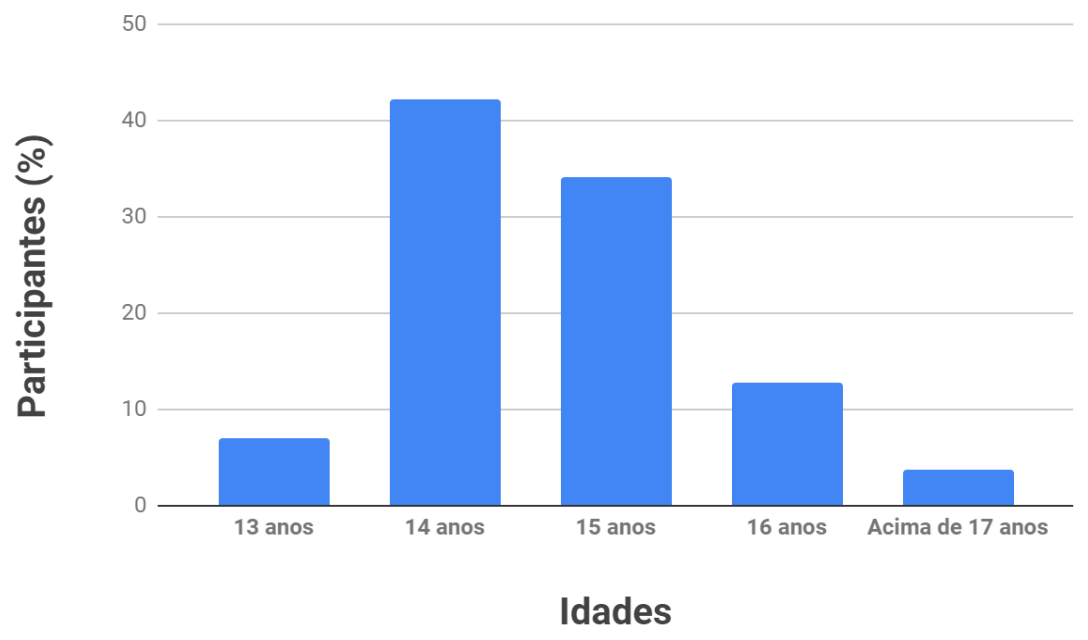

Fonte: Elaborada pelas autoras, 2019.

Mais do que a comparação de resultados entre os testes inicial e final de cada encontro, também oferecemos um espaço aos participantes para um feedback sobre as atividades desenvolvidas, para críticas, sugestões, elogios ou comentários diversos. De forma satisfatória, foi possível perceber que o projeto conseguiu atingir o objetivo proposto, através do notável interesse demonstrado pelos participantes e observado nos comentários deixados pelos alunos. Até o momento, todas as respostas obtidas foram muito positivas para a equipe de execução, expressando a satisfação dos alunos pela participação no projeto, pelo aprendizado e pela identificação da importância e relevância do tema trabalhado. Além disso, muitos dos participantes deixaram explícito o interesse por retornarem à instituição, na condição de aluno, além de relatarem algumas dificuldades enfrentadas durante a execução das oficinas. Nas Figuras 11 e 12, um resumo dos comentários recebidos através do pós-teste das modalidades de oficinas do ano de 2019 é apresentado. A seguir, é possível observar alguns dos comentários recebidos:

a) "Gostei bastante, ano que vem pretendo estudar aqui";

b) "Achei bem interessante, gostei bastante";

c) "Achei muito bom, gostei muito e levarei comigo essa experiência para sempre";

d) "Eu gostei porque podemos ver o quanto o raciocínio pode nos ajudar";

e) "Adorei a aula e quero muito fazer parte dessa instituição";

f) "Adorei a oficina, descobri que sou boa em lógica";

g) "Achei muito legal! Depois da oficina que entendi as atividades de lógica, muito bom e divertido";

h) "Eu gostei bastante, sempre gostei de informática e é uma coisa que me chama muita atenção, são todos bem-humorados e queridos". 
Figura 11 - Síntese dos comentários recebidos nas oficinas de computação desplugada de 2019

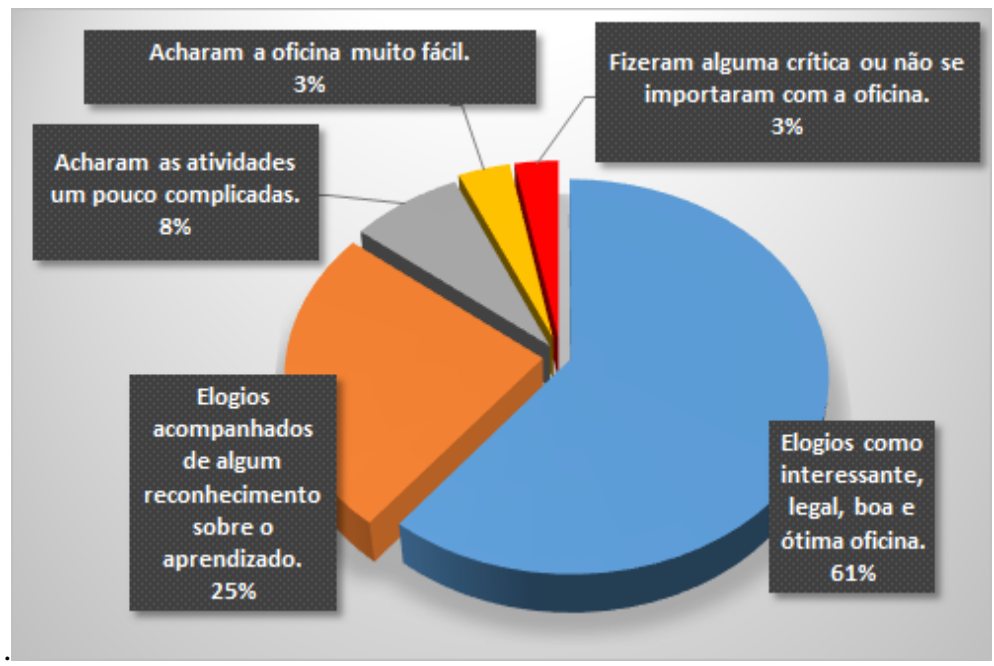

Fonte: Elaborada pelas autoras, 2019.

Figura 12 - Síntese dos comentários recebidos nas oficinas com recursos digitais de 2019

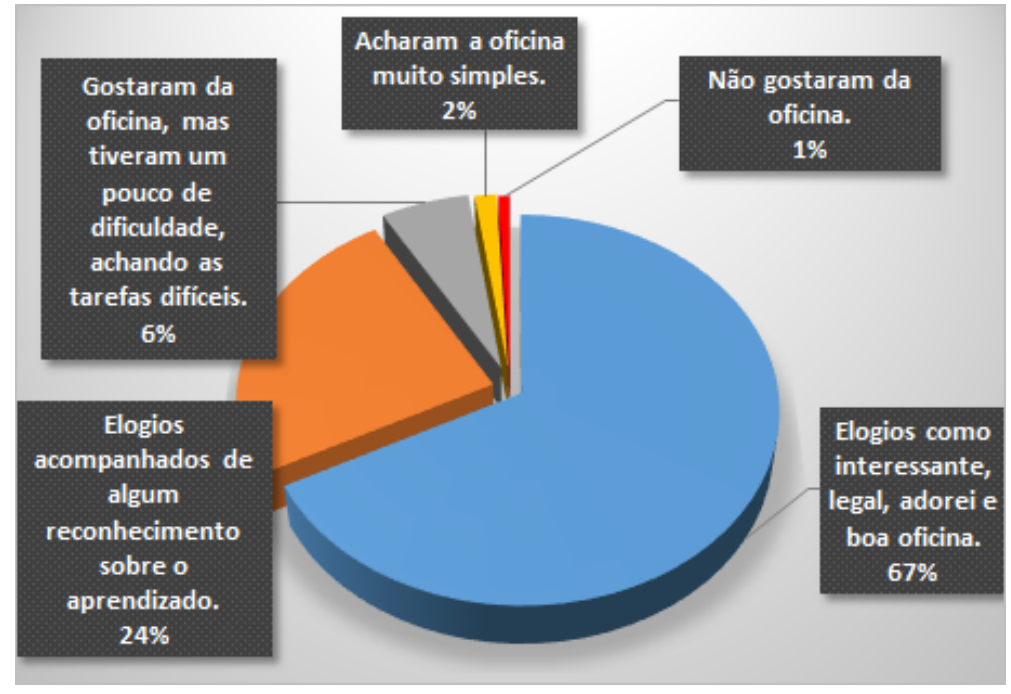

Fonte: Elaborada pelas autoras, 2019.

\section{Considerações finais}

Diante dos baixos índices de rendimento escolar no Brasil, que mostram a dificuldade dos estudantes em interpretar e compreender os mais diversos enunciados, apresentados pelos dados do IDEB, e diante do limitado uso da tecnologia pela população brasileira, apresentado pelo IBGE, surgiu a ideia da oferta de um projeto com o propósito de oferecer encontros para o estímulo do pensamento computacional e do raciocínio lógico. O pensamento computacional tem sido um tema muito explorado recentemente, pois seu uso está associado com as mais diversas tarefas do dia a dia, que exigem uma sequência de passos bem definidos para a resolução de problemas. O público-alvo das atividades desenvolvidas foi majoritariamente os alunos das séries finais do ensino fundamental. 
Oferecemos aos participantes a oportunidade de conhecer um pouco mais do universo tecnológico que nos permeia, a fim de que compreendam a relação do pensamento computacional com as funções que todos exercemos diariamente, promovendo momentos de aprendizado de forma integrada com a comunidade, além da divulgação da instituição promotora para apresentar aos participantes os cursos técnicos gratuitos oferecidos por ela, aos alunos que serão futuramente ingressantes no ensino médio.

Os encontros oferecidos foram classificados em dois tipos: encontros com computação desplugada e encontros com recursos digitais. Essa classificação se deu para que as escolas pudessem ser atendidas in loco, na própria escola, sem a necessidade de um laboratório de informática para o encontro desplugado, já que algumas delas não possuíam este recurso. Para o encontro digital, todas as escolas levaram seus alunos até o IFRS Campus Osório, e assim foi possível oportunizar aos alunos que conhecessem mais sobre a instituição, instigando especialmente as meninas participantes a se interessarem pela tecnologia da informação e comunicação, de forma lúdica. Espera-se que a experiência proporcionada aos estudantes possa contribuir para as suas respectivas decisões futuras, como por exemplo, optar pelo processo seletivo do IFRS Campus Osório para ingresso em um dos cursos técnicos oferecidos, integrados ao ensino médio.

Os encontros foram constituídos majoritariamente por atividades envolvendo jogos, requerendo a construção de uma sequência de instruções para se atingir um determinado objetivo, estimulando os participantes a buscarem por maneiras alternativas de desenvolver soluções para problemas cotidianos. Antes e depois de cada encontro, um teste foi realizado, a fim de comparar o aprendizado dos participantes. Foi possível observar que houve uma melhora na compreensão dos enunciados propostos, entre $14 \%$ e $30 \%$, evidenciando que as atividades desenvolvidas auxiliam na aprendizagem, permitindo uma maior compreensão sobre conteúdos trabalhados.

Além da troca de experiências em sala de aula, também foi um privilégio observar os retornos deixados pelos participantes, que ao final de cada encontro, forneceram relatos positivos sobre a participação nas oficinas, motivando a equipe de execução a dar continuidade ao projeto.

Deseja-se ainda levar este projeto para mais escolas, para que mais pessoas possam ter a oportunidade de receber uma proposta diferenciada de atividades lúdicas com o propósito de contribuir para a formação dos estudantes de forma mais integral e cidadã, com qualidade, compartilhando nossos saberes e experiências com a comunidade onde estamos inseridos. Também pretende-se analisar os resultados do processo seletivo de 2020/1, para observar se haverá procura pelos participantes para os cursos oferecidos pela instituição.

\section{Agradecimentos}

Agradecemos ao Instituto Federal de Educação, Ciência e Tecnologia do Rio Grande do Sul - Campus Osório pela oportunidade de desenvolvimento do projeto. Também agradecemos a todas as parcerias estabelecidas com as escolas da região, que permitiram a execução das atividades. 


\section{Referências}

ACHUTTI, Camila. Queremos mais mulheres na tecnologia já! Época Negócios, 08 mar. 2019. Disponível em: https://epocanegocios.globo.com/colunas/Novostempos/noticia/2019/03/queremos-mais-mulheres-na-tecnologia-ja.html. Acesso em: 17 out. 2019.

AGENDA 2020. Disponível em: https://agenda2020.com.br/. Acesso em: 02 ago. 2019.

BRAZILAUSTRALIA. Austrália Aprova Aulas de Programação ao invés de História e Geografia. 2015. Disponível em: https://www.brazilaustralia.com/australia-aprova-aulasprogramacao-inves-historia-geografia/. Acesso em: 17 out. 2019.

BELL, T.; WITTEN, I.; FELLOWS, M. Computer Science Unplugged: Ensinando Ciência da Computação sem o uso do Computador. 2019. Disponível em: http://csunplugged.org/. Acesso em: 20 set. 2019.

BRACKMANN, Christian. Desenvolvimento do Pensamento Computacional Através de Atividades Desplugadas na Educação Básica. Tese (Doutorado em Informática na Educação). 2017. Universidade Federal do Rio Grande do Sul (UFRGS), Porto Alegre, RS, Brasil, 2017. Disponível em: http://hdl.handle.net/10183/172208. Acesso em: 02 ago. 2019.

BRASIL. Base Nacional Comum Curricular (BNCC). Brasília: MEC. 2017. Disponível em: http://basenacionalcomum.mec.gov.br/a-base. Acesso em: 20 ago. 2019.

CHAMBERS, Sam. Escolas da Inglaterra ensinam alunos de 5 anos a programar. Exame, 16 out. 2014. Disponível em: https://exame.abril.com.br/tecnologia/escolas-da-inglaterraensinam-alunos-de-5-anos-a-programar/. Acesso em: 17 out. 2019.

CODE. Disponível em: https://code.org. Acesso em: 02 ago. 2019.

IBGE. Conheça o Brasil: População - Educação. 2018 Disponível em: https://educa.ibge.gov.br/jovens/conheca-o-brasil/populacao/18317-educacao.html. Acesso em: 10 ago. 2019.

FRABASILE, Daniela. Apenas 17\% dos programadores brasileiros são mulheres. Época, 05 fev. 2018. Disponível em:

https://epocanegocios.globo.com/Economia/noticia/2018/02/apenas-17-dos-programadoresbrasileiros-sao-mulheres.html. Acesso em: 17 out. 2019.

FRANK, Gustavo. Conheça Katie Bouman, a cientista responsável pela imagem do buraco negro. Folha de São Paulo, São Paulo, 10 abr. 2019. Disponível em:

https://www1.folha.uol.com.br/ciencia/2019/04/conheca-katie-bouman-a-cientistaresponsavel-pela-imagem-do-buraco-negro.shtml. Acesso em: 15 ago. 2019.

PENSAMENTO COMPUTACIONAL. Disponível em: http://computacional.com.br. Acesso em: 02 ago. 2019. 
SANTIAGO, Abinoan. Mesmo em crise, estados pagam acima do piso para professores; veja ranking. Gazeta do Povo, 04 abr. 2019. Disponível em:

https://www.gazetadopovo.com.br/educacao/mesmo-em-crise-estados-pagam-acima-do-pisopara-professores-veja-ranking/. Acesso em: 17 out. 2019.

SASS, Camila et al. Um relato sobre estratégias de motivação e ensino de lógica de programação para e por mulheres. Anais dos Workshops do Congresso Brasileiro de Informática na Educação, p. 659, out. 2018. ISSN 2316-8889. Disponível em: https://brie.org/pub/index.php/wcbie/article/view/8288. Acesso em: 20 set. 2019.

SILVA, Kennedy dos Santos; PEREIRA, Nícolas Pierim; ODAKURA, Valguima. Mapeamento Sistemático: estratégias para o ensino e aprendizagem do Pensamento Computacional no Brasil. Nuevas Ideas en Informática Educativa, V.14, p. 319 - 329, 2018. Disponível em: http://www.tise.cl/Volumen14/TISE2018/319.pdf. Acesso em: 20 set. 2019.

WERLICH, Claudia; KEMCZINSKI, Avanilde; GASPARINI, Isabela. Pensamento Computacional no Ensino Fundamental: um mapeamento sistemático. Nuevas Ideas en Informática Educativa, v.14, p. 375 - 384, 2018. Disponível em: http://www.tise.cl/Volumen14/TISE2018/375.pdf. Acesso em: 20 set. 2019.

Recebido em agosto de 2019.

Aprovado em outubro de 2019. 